\title{
PRÁTICAS DE FORMAÇÃO DE UM PROFESSOR DE EDUCAÇÃO FÍSICA EM CONTEXTO DE DESENVOLVIMENTO PROFISSIONAL NA EDUCAÇÃO INFANTIL
}

\author{
Kênia dos Santos Francelino \\ Universidade Federal do Espírito Santo, Vitória, Espirito Santo, Brasil. \\ Zenólia Christina Campos Figueiredo \\ Universidade Federal do Espírito Santo, Vitória, Espirito Santo, Brasil. \\ Nelson Figueiredo Andrade Filho \\ Universidade Federal do Espírito Santo, Vitória, Espirito Santo, Brasil.
}

\begin{abstract}
Resumo
O objetivo dessa investigação foi identificar, analisar e compreender as práticas de formação de um professor de Educação Física que atua na Educação Infantil de uma rede municipal de ensino, com fins a perceber os significados presentes nessas práticas, relacionando-os com $\mathrm{o}$ desenvolvimento profissional do professor. Este estudo caracteriza-se como qualitativo e utilizou a observação, os diálogos e a análise de documentos como instrumentos para a coleta de informações. As análises evidenciaram eixos estruturantes que se referem às situações cotidianas, as quais se expressam como práticas de autoformação relacionadas com o desenvolvimento profissional do professor, em meio às relações construídas por ele e aos registros realizados.

Palavras chave: Educação Física. Educação Infantil. Desenvolvimento Profissional.
\end{abstract}

\section{Introdução}

Buscamos identificar, analisar e compreender as práticas de formação de um professor de Educação Física que atua na Educação Infantil de uma rede municipal de ensino, com fins a perceber os significados presentes nessas práticas, relacionando-os com o desenvolvimento profissional do professor. Caminhamos em direção ao desafio de pensar a formação docente como campo profícuo, com possibilidades de indicar outras perspectivas epistemológicas para se pensar os currículos de formação inicial em Educação Física, bem como elementos para se pensar os rumos da formação continuada na área.

Essas práticas de formação em contexto de trabalho remetem ao que "[...] é específico na ação docente, isto é, o conjunto de comportamentos, conhecimentos, destrezas, atitudes e valores que constituem a especificidade de ser professor" (SACRISTÁN, 1999). São práticas que se referem a uma busca pessoal, portanto, não determinadas pelo sistema educacional, como os encontros de formação organizados e convocados pelas Secretarias de Ensino. 
Para a compreensão da questão de que trata esse artigo, abrimos um diálogo inicial sobre a formação da qual estamos falando, apresentamos uma breve descrição das escolhas metodológicas e tratamos, por fim, dos principais eixos de análise, referindo-nos às práticas de formação e às relações construídas pelo professor colaborador com as crianças, as pedagogas, os demais professores e auxiliares, e com os registros de aula.

\section{Para início de conversa... de qual formação estamos falando?}

Nóvoa (1995) ressalta o papel importante da formação inicial e continuada e do investimento pessoal e profissional do professor, quando diz que "[...] a formação deve estimular uma perspectiva crítico-reflexiva, que forneça aos professores os meios de um pensamento autônomo e que facilite as dinâmicas de autoformação participada" (p. 25). Esse processo de formação envolve alguns investimentos, como o esforço pessoal, um trabalho livre e criativo sobre sua trajetória e projetos próprios, visando à construção de uma identidade que também é uma identidade profissional.

Acrescenta ainda o autor que a formação é um processo de reflexão crítica sobre as práticas e de (re)construção contínua de uma identidade pessoal. Ela não se constrói por meio de acúmulos de conhecimentos ou técnicas, mas, sim, por "[...] um trabalho de reflexividade crítica, sobre as práticas e de (re)construção permanente de uma identidade pessoal" (1995, p. 25). Daí a importância do investimento pessoal e de não se desprezar o saber da experiência, uma vez que, quando nos referimos à reconstrução/ressignificação dessas práticas, pressupomos uma "construção" e "significação" iniciais, intimamente ligadas a vários contextos.

Com o intuito de entender os princípios que determinam a maneira como as experiências de autoformação de professores - entendidas como fundamentais no processo de formação continuada - têm se manifestado, principalmente no campo da Educação Física, quatro possibilidades são levantadas e analisadas detalhadamente por Heringer (2008): a) as instâncias formadoras, compreendidas pelas universidades de forma geral; b) a gestora central, entendida como as Secretarias de Educação e/ou Coordenações centrais de redes de ensino; c) a gestora local, relacionada com o coletivo de profissionais de cada unidade de ensino; d) as oriundas de iniciativa pessoal, ligadas ao professor.

Ponderando os quatro princípios aludidos, percebemos que a formação de um profissional configura-se como um processo contínuo, não linear, devendo acompanhar toda a trajetória de vida profissional, levando em consideração as ações educacionais inerentes à formação continuada, assim como as expectativas dos sujeitos envolvidos nesse processo de segmento e construção.

Com o intuito de melhorar a qualidade da educação, a formação continuada aparece como uma tentativa de solucionar boa parte dos problemas enfrentados pela educação em um cenário atual, onde a qualidade do ensino vem sendo questionada, diante dos resultados obtidos pelos indicativos de avaliação institucional. No entanto, essas ações de formação apresentam-se geralmente em forma de eventos pontuais, destacando-se as pa-

Pensar a Prática, Goiânia, v. 17, n. 3, p. 606-617, jul./set. 2014 
lestras, conferências e oficinas, bem como cursos de pequena ou longa duração. ${ }^{1}$ Apresentam-se ainda ações de educação à distância e envolvimento em projetos que reúnam profissionais de instituições formadoras (MONTEIRO; GIOVANNI, 2000).

Apesar do discurso, a gestão central, juntamente com as instâncias formadoras, não tem demonstrado preocupação em modificar o formato de oferta da formação continuada. Tal constatação sustenta-se em estudos que evidenciam uma atualidade em que "[...] as instâncias de gestão central assumem o papel principal na organização e definição dos espaços de formação, cabendo às instâncias formadoras o papel de assessoria acadêmica" (HERINGER, 2008, p.33). Desse modo, a gestão central assume, de forma sistemática, a condução do processo formativo, detendo a centralização das ações formadoras, pois, considerando a relativa autonomia que os professores universitários - assessores demonstram em fazer parte desses movimentos de formação, direta ou indiretamente, eles tendem a satisfazer os interesses político-ideológicos definidos nessa instância de poder central (HERINGER, 2008).

Diferentemente dessa possibilidade/formato de formação continuada, este estudo pauta-se pelas possibilidades da autoformação, evidenciada e embasada na autonomia e protagonismo dos professores. Afinal, eles são os atores que devem participar ativamente, decidir os objetivos e organizar o funcionamento do processo da sua própria formação. A eles cabe a responsabilidade e o compromisso em articular situações que favoreçam trocas de experiências e vivências relacionadas com o âmbito profissional, planejamentos individuais e coletivos, interações entre os profissionais da educação que atuam de forma a compartilhar as práticas desenvolvidas na unidade de ensino, bem como provocar reflexões sobre as práticas cotidianas efetivadas, perspectivando a produção de conhecimento que reoriente a prática pedagógica.

$\mathrm{Na}$ unidade de ensino pesquisada, pudemos acompanhar de perto alguns desses momentos de formação ou autoformação. Neste estudo, tivemos como foco observar e acompanhar um professor de Educação Física do Centro Municipal de Educação Infantil selecionado. Ao nos depararmos com o dia a dia desse docente, com as dinâmicas cotidianas e com as interações estabelecidas principalmente com as outras professoras, passamos a observar a evolução dessas práticas de formação, assim como de alguns momentos pontuais de efetivação de práticas cotidianas. ${ }^{2}$

1 A esse atribuímos os cursos de aperfeiçoamento e especialização.

2 Práticas essas vivenciadas pelas crianças em sua rotina diária, e pelos profissionais que nessa escola atuam - experimentando as práticas vividas pelas crianças, como também pelos pais em momentos articulados pela unidade escolar, de modo a compartilhar com as famílias dos alunos um pouco do que esse espaço tem proporcionado a eles.

Pensar a Prática, Goiânia, v. 17, n. 3, p. 606-617, jul./set. 2014 


\section{Caminhos metodológicos percorridos}

Realizamos um levantamento na Secretaria Municipal de Educação e obtivemos a relação dos 44 Centros Municipais de Educação Infantil (CMEI), incluindo os nomes dos 76 professores de Educação Física efetivos que atuavam nesses Centros.

De posse dessa listagem, aplicamos um questionário aos professores, com os objetivos de obter uma visão geral sobre suas concepções, práticas e investimentos relacionados com a formação continuada e de filtrar/selecionar um sujeito colaborador que faria parte da etapa seguinte do trabalho de campo: acompanhamento das práticas de formação continuada de um professor em contexto institucional na Educação Infantil.

No instrumento constavam cinco questões abertas que contribuíram para uma primeira visão mais horizontal (ANDRÉ, 2007), no que se refere à concepção geral de formação continuada desses sujeitos e das suas práticas de formação.

Visitamos pessoalmente 41 dos 44 CMEIs e entregamos o questionário a 62 professores, em meio aos 76 constantes na listagem. Desse total, tivemos o retorno de 39 questionários, equivalentes a $62,9 \%$ da amostra pesquisada. Mesmo diante de todos os desafios e contratempos enfrentados no período de visitação, o contato direto estabelecido com os docentes, os gestores e as pedagogas contribuiu para que pudéssemos ter um conhecimento mais ampliado do sistema de ensino investigado e das práticas cotidianas vivenciadas nas instituições educativas.

Em seguida, passamos para a etapa de análise e categorização das respostas colhidas, com a finalidade de chegar a um professor colaborador que seria acompanhado nas suas práticas de formação continuada no contexto da sua atuação. Nessa análise, a finalidade foi identificar qual docente se destacava pela busca autônoma por formação continuada, fornecendo indicativos que atendessem o objetivo da pesquisa, indo além da participação em eventos pontuais ${ }^{3}$ ou nos oferecidos pela instituição.

Na primeira questão solicitamos que os sujeitos descrevessem sua concepção de formação continuada. ${ }^{4}$ Tratando-a, percebemos que 15 profissionais $(41,66 \%$ desses colaboradores) apresentaram uma concepção restrita, enquanto 21 outros $(58,33 \%)$ demonstraram ter uma concepção ampliada. Em face da perspectiva ampliada que apresentaram, escolhemos analisar integralmente os questionários desses 21 colaboradores. A perspectiva de investimento pessoal e profissional e a mobilização de diferentes práticas e de recursos em favor da autoformação estavam fortemente presentes em três questionários desse lote.

3 Esses eventos são entendidos como seminários, congressos, palestras, conferências, oficinas, cursos de curta duração e de atualização.

4 Consideramos, então, que os sujeitos que se restringirem a essas respostas fazem parte do grupo que apresenta uma concepção restrita de formação continuada, enquanto os que a enxergam para além dos muros escolares, como práticas de formação, não só como profissionais, mas também como sujeitos que buscam crescimento por iniciativas e organizações próprias, se enquadram numa concepção de formação continuada mais ampla.

Pensar a Prática, Goiânia, v. 17, n. 3, p. 606-617, jul./set. 2014 
Com relação a esses três últimos instrumentos, duas professoras e um professor sinalizaram participar, de modo singular, de grupos de estudos, encontros para além dos planejamentos e reuniões que aconteciam nas instituições de ensino em que trabalhavam. Após várias conversas com os três, decidimos convidar o professor. Ele aceitou participar prontamente como colaborador típico da nossa pesquisa, bem como assinou os termos de consentimento e de responsabilidade. Também colhemos assinaturas de consentimento da Diretora da instituição, na qual a permanência de um semestre completo, turno da tarde, foi necessária ao desenvolvimento do estudo.

\section{Interpretação possível sobre práticas de formação em contextos de desenvolvimento profissional}

Após analisar os registros das observações, das conversas informais, das entrevistas, dos planejamentos individuais e coletivos, da materialização dos planejamentos, apresentamos alguns indicativos percebidos e compreendidos como eixos de análise estruturantes deste estudo. Tais eixos se referem às situações cotidianamente observadas que se expressam como práticas de formação relacionadas com o desenvolvimento profissional do professor, em meio às relações e aos registros.

O professor e suas relações: consigo mesmo e com os outros, com fins à organização das situações de ensino e aprendizagem

Este primeiro eixo de análise nos remete a uma reflexão de como o professor colaborador da pesquisa dialoga com ele próprio e com os outros na tentativa de constituir-se como docente, na construção de novas possibilidades de trabalho pedagógico, num esforço pessoal de reflexão e de autoformação sobre a sua ação em variados aspectos.

$\mathrm{O}$ professor colaborador apresenta algumas inquietações quanto às suas práticas profissionais, que o fazem refletir sobre algumas possibilidades e alternativas de trabalho: "O que tenho à minha disposição com relação ao espaço, tempo e materiais? $\mathrm{O}$ que posso realizar? Como seria sua materialização e metodologias a serem utilizadas? O que de fato quero fazer e o que preciso para realizá-lo? Que ferramentas utilizar levando sempre em conta a construção e o acesso às culturas (múltiplas, diversidade, cultura corporal, música, arte, teatro)? Dentro dessa cultura infantil (seja ela oriental, seja ocidental) como posso estar possibilitando seu acesso às crianças, pensando num "projeto" com duração inicial de três anos? (ALEXANDRE ${ }^{5}, 12-3-2009$ ).

Ao estabelecer um diálogo intrínseco de questões externas, de natureza material ou humana, Alexandre mobiliza saberes, experiências e expectativas de como se constituir professor ao longo de sua docência, investigando sua própria atividade e, a partir dela, construindo e (re)significando novos saberes num processo contínuo.

5 Nome próprio do professor, com divulgação devidamente autorizada. O professor não quis utilizar um nome fictício, segundo ele, porque não havia motivos para não revelar o seu nome.

Pensar a Prática, Goiânia, v. 17, n. 3, p. 606-617, jul./set. 2014 
Ao organizar e planejar estratégias pedagógicas, ele analisa e sistematiza questões relacionadas com o antes e o depois da materialização da prática, assim como se preocupa em acompanhar os vários processos envolvidos no contexto: planejamentos escritos e sistematizados, bem como o desenvolvimento das aulas; os conteúdos a serem trabalhados, considerando as características dessa modalidade de ensino e a especificidade da área de atuação; reflexões da e na docência; a receptividade e o envolvimento das crianças nas atividades propostas; a reflexão sobre o que de fato atendeu às perspectivas iniciais, levantando outras possibilidades de efetivação e (re)significação; o compromisso com a educação e as necessidades de registrar o que foi vivenciado com as crianças; a preocupação de produzir textos e artigos acadêmicos com o intuito de divulgar experiências e ampliar o diálogo sobre as problemáticas presentes no campo da Educação Infantil com outras áreas de conhecimento.

As percepções e reflexões do professor, mesmo que de caráter pessoal, não se dão de forma isolada. Existem redes de mobilização dos saberes que se constroem ao longo dessa experiência profissional e pessoal. Pudemos acompanhar ações relacionadas com essas redes. Participamos de uma oficina de sucata em que uma professora regente de classe direcionou a confecção de um boneco de fantoche que seria mais uma alternativa de tentar seduzir a criança nos momentos de contação de histórias. Várias foram as situações de troca de práticas significativas entre os docentes e equipe técnico-pedagógica dessa unidade de ensino nesses espaços de formação. Os professores, por sua vez, sempre socializavam a documentação das suas práticas por meio de portfólio, relatos e artigos acadêmicos.

Em nossas observações, percebemos a preocupação de Alexandre em proporcionar às crianças diferentes vivências, mesmo com objetos e materiais já conhecidos e manipulados por elas. O professor pensava sempre e manifestava seu anseio em articular situações que favorecessem a participação e o envolvimento das crianças em momentos de experiências, descobertas, construção de conhecimentos e (re)significações. Suas escolhas pedagógicas se originavam não só das interações que estabelecia com o corpo técnico pedagógico e administrativo do CMEI, mas também com as dinamizadoras parceiras, com as crianças e outros profissionais que ali desenvolvem seu trabalho. "[...] partindo do que é seu, do que sabe e controla: suas práticas, seus produtos e seu trabalho" (ARROYO, 2004, p. 150).

No processo de busca e (re)significações constantes, é que são mobilizados pelo professor elementos como: a reflexão da sua prática e trajetória de vida; as buscas por respostas de inquietações oriundas desse campo de atuação; a sua procura autônoma e alternativa de novas práticas de formação - autoformação; e as suas relações tecidas e estabelecidas ao longo desse percurso.

\section{O professor, os planejamentos e os registros de aula}

Nossa intenção nesse eixo de análise perpassa por aprofundar algumas questões acerca das relações estabelecidas por Alexandre com os registros pessoais que produziu 
no contexto da Educação Infantil. Entendemos ser essa prática mais um cordame da rede mobilizadora no processo de autoformação no qual ele está inserido, compreendendo a contribuição dos registros para a sua formação e o seu desenvolvimento profissional.

Diante das variadas possibilidades de registros produzidos e sistematizados pelos professores, como diários de classe, atas de reuniões, livros de registros de trabalho coletivo, caderno de registro de plano de aula, portfólio, entre outros, acreditamos que sua construção é um importante indicativo nas diferentes funções do trabalho pedagógico.

Assim como Lopes (2009), entendemos que o caderno de registro diário caracteriza-se como um material extremamente importante, capaz de representar a prática pedagógica docente desenvolvida e a história vivida de um grupo. Nele podemos encontrar narrativas de atividades desenvolvidas, objetivos sugeridos para aquela proposta pedagógica, descrições de aula, observações sobre as crianças e suas aceitações ou não do que lhes foi propiciado.

Tivemos acesso a três cadernos de registros do professor, mas optamos por explorar informações e narrativas do caderno atual como fonte de dados. Este constitui-se como um "espaço" particular de significações atribuídas pelo docente, onde ele apresenta planos de atividades a serem desenvolvidos, objetivos propostos, observações pessoais e, em alguns momentos, coletivas sobre as aulas e o envolvimento das crianças, encaminhamentos e reformulações pensadas e executadas dia a dia, bem como fichamentos de leituras pertinentes aos seus estudos.

Percebemos nos relatos planejamentos de intervenções e problematizações nas quais as crianças puderam fazer (re)leituras diante do que lhes foi oferecido. Entendemos que "[...] planejar é preparar bem a ação, acompanhando-a para confirmar ou corrigir o decidido, revendo-a, criticando a preparação feita, depois de tudo terminado" (NEIRA, 2004, p.82).

Em seus planejamentos e registros, percebemos que Alexandre considera significativas as questões curriculares acima mencionadas. Neles é possível ter uma ideia da efetivação de suas práticas por meio dos seus escritos, análises e reflexões sobre as aulas dadas.

A inquietação do professor relacionada com a efetivação do que foi anteriormente planejado, com o resultado das práticas pedagógicas e, por vezes, com o interesse e significação das crianças com relação à atividade proposta, o levava a (re)planejar ações e buscar alternativas de trabalho. Tal reflexão, mudança e busca de possibilidades de trabalho pedagógico se davam de forma individual e/ou coletiva.

O docente encontra, na elaboração de seus planos de aula, oportunidades de refletir sobre os educandos, suas características individuais e coletivas, suas necessidades em relação a objetivos e intenções perseguidas, o que possibilita uma melhor organização da prática e, com isso, favorece a aprendizagem.

Apesar de termos como foco os momentos de planejamento, sistematização e vivências das práticas de formação construídas pelo profissional, é interessante ressaltar nossas expectativas a cada semana em acompanhar e também vivenciar as práticas docentes do professor Alexandre. Em seus planejamentos, ele mobiliza conhecimentos e articu- 
la possibilidades de práticas docentes, tendo como preocupação potencializar situações de envolvimento e encantamento das crianças, bem como proporcionar situações onde elas possam (re)significar suas experiências vividas.

Em uma situação de planejamento dos professores, antes da formação direcionada pela diretora e pedagogas, eles decidiram que se organizariam para trabalhar semanalmente no primeiro semestre com atividades temáticas que despertassem curiosidades nas crianças em experimentar o que estava sendo proposto. Sendo assim, optaram por trabalhar com bolas de soprar sabão no pátio da instituição. Em seus registros, o professor relata o que de fato aconteceu, pontuando aspectos positivos e negativos para tentar aprimorar em uma próxima aula.

O professor, em suas anotações, relata seu dia, reflete sobre acontecimentos, crianças e sobre a sua própria atuação. Refere-se a um "[...] espaço de investigação, questionamento, introspecção, comunicação e autoria do processo pedagógico" (LOPES, 2009, p. 119). Alexandre reconhece o registro como uma importante ferramenta de interlocução entre a teoria e a prática, entre os conhecimentos construídos e a efetivação do seu ser e estar professor.

Sua prática de fazer esses registros, ao longo dos três anos atuando na Educação Infantil, passou por transformações de significados. Inicialmente o professor buscava registrar tudo que era possível, de modo a tentar entender o que estava fazendo naquele espaço e tempo, pouco conhecido, tentando evidenciar as tensões advindas da teoria utilizada e da prática efetivada. Os primeiros registros eram tímidos. Versavam sobre o que aconteceu durante a aula, evidenciando práticas, o comportamento dos alunos e das turmas, o desenvolvimento das aulas. Nesse andamento, rememorava as práticas executadas a cada planejamento. Inicialmente não era sistemático, mas considerava satisfatórias as narrativas. Para além dos registros em caderno, fazia uso do portfólio e, de Outubro de 2007 em diante, passou a registrar também por meio de vídeos, produções (artigos) e portfólio digital (web fólio).

Neste eixo, analisamos as variadas formas de registros utilizadas pelo professor Alexandre. Com essa análise, além de percebermos que tais formas de registro foram construídas no processo de formação continuada dele, percebemos também que sua produção perpassa por todos os momentos da prática de formação, desde o planejamento às ações, à reflexão e sistematização de experiências, às divulgações do trabalho aos pais, à comunidade escolar e aos outros profissionais da educação. Percebemos que o ato de registrar, para ele, é um instrumento singular ao seu desenvolvimento como profissional docente. É o modo com que ele se possibilita, se permite planejar, agir, refletir, construir, autoformar-se e constituir-se professor.

\section{O professor e suas relações com as crianças}

Nesse terceiro eixo, buscamos avaliar a relação estabelecida entre Alexandre e as crianças nos momentos de planejamento, desenvolvimento da ação pedagógica e reflexão/avaliação da prática realizada, no intuito de compreender quais contribuições advin- 
das dessa relação favorecem o processo de (re)significação das práticas de formação continuada do docente.

A criatividade e ousadia em planejar e criar novas possibilidades de objetos simples e de fácil acesso, bem como as problematizações lançadas às crianças em situações pedagógicas diversas, proporcionando a elas possibilidades de ressignificar o que está posto, são aspectos que se destacam na docência desse profissional. $\mathrm{O}$ ir além das possibilidades impostas por determinado material ou atividade articulada pelo docente ou mobilizada pelas crianças é uma contribuição significativa para elas e outros docentes e profissionais envolvidos no processo ensino-aprendizagem. A preocupação com a segurança e bem-estar das crianças se faz presente e é perceptível em todas as ideias de materialização das práticas educativas cotidianas.

Acompanhamos algumas dessas práticas educativas levando em consideração que o professor também as reconhece como importantes para suas análises, reflexões e avaliações posteriores. Em seu planejamento, o professor lança mão de algumas estratégias, invenções e recursos que conduzem as ações de ensino e à busca pela realização dos objetivos traçados. Entretanto, Freitas nos alerta para perceber que "[...] é durante a realização da aula, na relação estabelecida com as crianças, que ele vai saber se "os caminhos" propostos levaram aos resultados esperados" (FREITAS, 2008, p. 168).

Ao refletir sobre o que foi planejado e materializado e sobre os resultados decorrentes do processo de ação-reflexão-ação vivido, Alexandre mobilizou conhecimentos que foram construídos ao longo da sua trajetória acadêmica e profissional, do seu processo de constituir-se docente, se colocando em análise quando se propôs a documentar suas práticas de formação. Desse processo, entendemos que na relação professor-aluno, com os fios que são tecidos dia a dia, novos olhares são lançados à luz do que se propõe e de fato se materializa, para ambos os sujeitos envolvidos.

\section{Considerações Finais}

Essa investigação permitiu perceber que contextualizar as práticas de formação ou autoformação e suas redes mobilizadoras, no âmbito do processo de desenvolvimento profissional, decorre do entendimento de que elas se processam como algo dinâmico, relacional, que vai além dos componentes técnicos e normativos, geralmente impostos aos professores pelas instâncias de formação, que, quase sempre, ignoram a dimensão subjetiva do trabalho docente e as situações comuns enfrentadas pelos profissionais em suas práticas cotidianas. Essa contextualização também propicia um caráter orgânico às etapas formativas vividas pelo docente, assegurando-lhe uma dinâmica contínua e progressiva.

A pesquisa também nos permitiu identificar que as ações de formação estão intimamente relacionadas, são criadas e recriadas cotidianamente, atribuindo sentido e significados às situações vividas individual e coletivamente, de modo a reconhecer ferramentas utilizadas no cotidiano que contribuem para o crescimento pessoal e profissional do professor. Alexandre reconheceu que, nessas interações, ele se fez autor das suas teorias e práticas como sujeito docente em constante construção nesse campo de atuação.

Pensar a Prática, Goiânia, v. 17, n. 3, p. 606-617, jul./set. 2014 
O professor, ao estabelecer diálogos intrínsecos sobre questões externas, mobiliza saberes, experiências e expectativas favoráveis para se constituir professor, ao longo de sua docência. Investigando sua própria atividade, ele consegue construir e (re)significar seus saberes em um processo contínuo. Refletindo, ele percebe a si mesmo, os outros e os elementos que o cercam. $\mathrm{O}$ ato de refletir sobre a sua formação, o seu estar na docência e constituir-se como docente, a materialização das suas práticas pedagógicas e suas implicações, possibilita a Alexandre ampliar as possibilidades em busca de conhecimentos, em um processo de autonomia, autoria, autoformação pessoal e profissional.

No que se refere às suas relações com os planejamentos e registros de aula, ao planejar, executar e avaliar, por meio da observação, da reflexão e dos relatos de experiências, Alexandre tem a possibilidade de explorar as dimensões formadoras subjetivas proporcionadas pelo registro. Ao documentar, lança mão de saberes e memórias construídas e reconstruídas em sua trajetória de vida profissional.

Analisando o professor e suas relações com as crianças em situações de planejamento, desenvolvimento da ação pedagógica e reflexão/avaliação da prática desenvolvida apreendemos que tais interações, em seus diferentes tempos e espaços, contribuem significativamente para que o docente avance no processo de (re)significação das práticas de formação construídas e mobilizadas por ele. Sua criatividade e ousadia em planejar e criar novas possibilidades de ressignificação do que está posto é um diferencial em suas buscas. Ao refletir sobre a proposta pedagógica de forma intencional o docente chama a atenção para outros saberes que não estavam no seu plano de curso, se autoavaliando durante a aula, induzido pela observação das expressões das crianças e pela relação de conhecimento estabelecida no processo ensino-aprendizagem.

\title{
FORMATION PRACTICES OF A PHYSICAL EDUCATION PROFESSOR IN CONTEXT OF PROFESSIONAL DEVELOPMENT IN CHILDHOOD EDUCATION
}

\begin{abstract}
The objective of this investigation was to identify, analyze and comprehend the formation practices of a Physical Education professor, that acts at municipal schools' Childhood Education, with the intention of perceiving the meanings present on this practices, relating them with the professional development of the professor. Characterizes as a qualitative study and uses the observation, dialogs and the analysis of documents to collect information. The analyzes showed structural axes, which relate to everyday situations that are expressed as practices of self-formation related to the teacher's professional development, amid the relationships built by him and logs achieved.

Keywords: Physical Education. Childhood Education. Professional Development.
\end{abstract}

Pensar a Prática, Goiânia, v. 17, n. 3, p. 606-617, jul./set. 2014 


\title{
PRÁCTICAS DE FORMATIÓN DE UN PROFESOR DE EDUCACIÓN FÍSICA EN EL CONTEXTO DE DESARROLLO PROFESIONAL EN LA EDUCACIÓN INFANTIL
}

\begin{abstract}
Resumen
El objetivo de esta investigación fue identificar, analizar y comprender la práctica de formación de un profesor de Educación Física, que opera en la Educación Infantil de unos fines educativos municipales, para darse cuenta de los significados presentes en estas prácticas, su vinculación con el desarrollo profesional de los profesores. Caracterizado como estudio cualitativo utiliza la observación, el diálogo y el análisis de documentos como instrumentos para la recopilación de información. Los análisis mostraron ejes estructurales, que se refieren a situaciones cotidianas que se expresan como prácticas de autoformación relacionadas con desarrollo profesional de los profesor, en medio de las relaciones establecidas por él e registros hecho.
\end{abstract}

Palabras-claves: Educación Física. Educación Infantil. Desarrollo Profesional.

\section{Referências}

ANDRADE FILHO, Nelson Figueiredo de. Perspectiva pedagógica da educação física para a educação infantil: provocações. In: GRUNENNVALDT, José Tarcísio et al. (Org.). Educação física esporte e sociedade: temas emergentes. São Cristóvão: Universidade Federal do Sergipe, p. 23-39, 2007.

ANDRÉ, Marli Eliza Dalmazo Afonso de. Etnografia da prática escolar. 12. ed. Campinas: Papirus, 2007.

ARROYO, M. G. Ofício de mestre: imagens e auto-imagens. 7. ed. Petrópolis, RJ: Vozes, 2004.

FREITAS, Amanda Fonseca Soares. Corpo e conhecimento na educação infantil. In: ANDRADE FILHO, Nelson Figueiredo de Andrade; SCHNEIDER, Omar (Org.). Educação Física para a Educação Infantil: conhecimento e especificidade. São Cristóvão: UFS, p. 143-176, 2008.

HERINGER, Dionésio Anito Teixeira. Formação continuada de professores de educação física: ocultações, contradições e possibilidades. 2008. Dissertação (Mestrado em Educação Física) - Programa de Pós-Graduação em Educação Física, Universidade Federal do Espírito Santo, Vitória, 2008.

LOPES, Amanda Cristina Teagno. Educação infantil e registro de práticas. São Paulo: Cortez, 2009.

Pensar a Prática, Goiânia, v. 17, n. 3, p. 606-617, jul./set. 2014 
MONTEIRO, Dirce Charara; GIOVANNI, Luciana Maria. Formação continuada de professores: o desafio metodológico. In: MARIN, Alda Junqueira (Org.). Educação continuada: reflexões alternativas. Campinas, SP: Papirus, p. 129-143, 2000.

NEIRA, Marcos Garcia. Educação física na educação infantil: algumas considerações para a elaboração de um currículo coerente com a escola democrática. In: ANDRADE FILHO, Nelson Figueiredo de Andrade; SCHNEIDER, Omar (Org.). Educação física para a educação infantil: conhecimento e especificidade. São Cristóvão: UFS, p. 45-96, 2008.

NÒVOA, António. Formação de professores e profissão docente. In: NÒVOA, António (Org.). Os professores e a sua formação. 2. ed. Lisboa: Publicações Dom Quixote, p. 15-33, 1995.

SACRISTÁN, J. Gimeno. Consciência e acção sobre a prática como libertação profissional dos professores. In: NÓVOA, Antônio (Org.). Profissão professor. 2 ed. Porto: Porto Editora, p. 63-92, 1999.

Recebido em: 26/09/2013

Revisado em: 08/03/2014

Aprovado em: 10/06/2014

Endereço para correspondência:

zenoliavix@gmail.com

Zenólia Christina Campos Figueiredo

Universidade Federal do Espírito Santo, Centro de Educação Física e Desportos.

Av. Fernando Ferrari S/N

Goiabeiras, 29000-300 - Vitoria, ES - Brasil 